\title{
A Prospective Study of Posterior (Transpedicular) Approach versus Anterior (Transthoracic) Thoracoabdominal) Approach for Posttraumatic Compression Fracture of Thoracolumbar Vertebra in a Tertiary Care Center: Comparison of Clinical and Radiological Outcomes
}

\author{
Rahul Varshney ${ }^{1}$ Parthasarathi Datta ${ }^{2}$ Pulak Deb $^{3}$ \\ ${ }^{1}$ Department of Neurosurgery, Postgraduate Institute of Medical \\ Education and Research, New Delhi, India \\ 2Department of Neurosurgery, NRS Medical College and Hospital, \\ Kolkata, West Bengal, India \\ ${ }^{3}$ Department of Neurosurgery, Calcutta National Medical College \\ and Hospital, Kolkata, West Bengal, India
}

Indian J Neurotrauma 2021;18:111-118.

\section{Santanu Ghosh ${ }^{3}$}

\begin{abstract}
Address for correspondence Rahul Varshney, MCh, Department of Neurosurgery, Room No. 206, Postgraduate Institute of Medical Education and Research, Dr RML Hospital, New Delhi 110001, India (e-mail: rahul_varshney1@rediffmail.com).
\end{abstract}

\begin{abstract}
Keywords

- transthoracic

- kyphosis

- Cobb's angle

- titanium mesh

- transthoracic

Objective The aim of this article was to analyze the clinical and radiological outcomes of transpedicular decompression (posterior approach) and anterolateral approach in patients with traumatic thoracolumbar spinal injuries.

Materials and Methods It was a prospective study of patients with fractures of dorsolumbar spine from December 2011 to December 2013. A total of 60 patients with traumatic spinal injuries were admitted during the study period (December 2011-2013), of which 51 cases were finally selected and taken for operations while 3 were eventually lost in follow-up. Twenty patients were operated by anterolateral approach, titanium mesh cage, and fixation with bicortical screws. Twenty-eight patients were treated with posterior approach and transpedicular screw fixation. Clinical and radiographic evaluations were performed on all 48 patients before and after surgery.

Results There were 48 patients of thoracolumbar burst fractures with 40 male and 8 female patients. Range of follow-up was from 1 month to 20 months, with a mean of 7.4. Preoperatively in anterior group, $65 \%$ of the patients were bed ridden, $20 \%$ patients were able to walk with support, and $15 \%$ of the patients were able to walk without support. In posterior group, $78.57 \%$ patients were bed ridden, $10.71 \%$ were able to walk with support, and $10.71 \%$ patients were able to walk without support. Kyphotic angle changes were seen in 16 patients out of 18 in anterior group and 20 patients in posterior group out of 25 . Out of 18 patients in anterior group, 14 showed reduction in kyphotic angle of 10 to 100 (improvement), with mean improvement of 4.070. In posterior group, 7 patients showed improvement of 10 to 80 (reduction in kyphotic angle) whereas 13 patients showed deterioration of 1 to 120 . The mean improvement was 2.140 in 7 patients and mean deterioration was
\end{abstract}

published online

September 14, 2020
DOI https://doi.org/

$10.1055 / \mathrm{s}-0040-1714188$ ISSN 0973-0508.
(C) 2020. Neurotrauma Society of India.

This is an open access article published by Thieme under the terms of the Creative Commons Attribution-NonDerivative-NonCommercial-License, permitting copying and reproduction so long as the original work is given appropriate credit. Contents may not be used for commercial purposes, or adapted, remixed, transformed or built upon. (https://creativecommons.org/licenses/by-nc-nd/4.0/).

Thieme Medical and Scientific Publishers Pvt. Ltd. A-12, 2nd Floor, Sector 2, Noida-201301 UP, India 
4.920. No statistical difference was found $(p>0.05)$ regarding improvement in urinary incontinence during the follow-up period.

Conclusion There are significant differences in anterior and posterior approaches in terms of clinical improvement. Compared with posterior approach, the anterolateral approach can reduce fusion segment and well maintain the kyphosis correction. The selection of treatment should be based on clinical and radiological findings, including neurological deficit.

\section{Introduction}

Due to high frequency of motor vehicle accidents and work place injuries, spine fractures are common in today's world. Following spinal injuries, there is $7 \%$ mortality rate. The upper thoracic region (T1-T8) is rigid due to the rib cage, which provides stability. The transition zone extends from T9 to $\mathrm{L} 2$, which is the transition between the rigid and kyphotic upper thoracic spine and the flexible lordotic lumbar spine. This is where most injuries occur.

The treatment of thoracolumbar fractures can be either conservative or surgical. There were no advantages reported by Wood et $\mathrm{al}^{1}$ for operative stabilization compared with nonoperative treatment in patient with thoracolumbar burst fractures in neurologically intact patients. However, Siebenga et $\mathrm{al}^{2}$ reported significantly higher radiologic kyphosis and significantly higher pain scores after nonoperative treatment.

Unstable thoracolumbar burst fractures may be treated with anterior, posterior, or circumferential fusion. There are no clear-cut guidelines regarding surgical management of unstable thoracolumbar fractures as the treatment protocol is decided taking into account multiple factors like fracture pattern, canal compromise, the severity of neurological injury, and surgeon's experience. All these parameters affect the decision regarding the surgical approach, with each parameter being an indication for one or the other approach. Therefore, no consensus has been reached about the ideal treatment approach.

Although there are several reports of thoracolumbar fractures, most studies are based on only one surgical method or on internal fixation. ${ }^{3}$ There is a paucity of the evidence-based guidelines for the treatment of these fractures and, for a better comparison of surgical techniques, randomized controlled trials are necessary. ${ }^{4}$

We present a prospective analysis of case series of patients who underwent either anterior or posterior decompression or stabilization in our tertiary care center. Our study was performed (1) to compare the neurological outcome of patients undergoing surgery by either approaches and (2) to compare the radiological outcomes of anterior and posterior operations.

\section{Aim}

1. To study the age and sex distribution of thoracolumbar spinal injuries in our patient population.
2. To analyze the results of transpedicular decompression and anterior thoracic approach in our patients with traumatic thoracolumbar spinal injuries in terms of:

a. Kyphotic deformity.

b. Motor and sensory improvement.

c. Bladder and bowl control.

\section{Materials and Methods}

This was a prospective study of patients with fractures of dorsolumbar spine conducted at a tertiary care neurosurgical center from December 2011 to December 2013. Institutional Review Board approval and informed consent were obtained. Analysis of our surgical results was done as per the following:

1. Clinical parameters: Pre- and postoperative results according to American Spinal Injury Association (ASIA) classification.

2. Radiological parameters: Pre- and postoperative radiological results in terms of spinal deformity (kyphosis) was studied by Cobb's angle.

\section{Inclusion Criteria}

- Patients with spinal canal compression caused by bony fragments, who demonstrated worsening of neurological status.

\section{For Anterior Approach}

- Significant anterior compression of the spinal cord (canal encroachment more than 50\%) \pm kyphotic deformity.

- Absence of thoracic or abdominal pathologies that hinder the transthoracic or retroperitoneal approaches.

- Anterior and middle column disruption.

\section{For Posterior Approach}

- Significant posterior compression of the spinal cord \pm kyphotic deformity.

- Patient condition not permitting lengthy anterior procedure.

- Posterior column disruption.

- Canal encroachment $<50 \%$.

\section{Exclusion Criteria}

1. Patients not willing to give consent.

2. Patients with age less than 18 years. 
3. Patients with complete cord transaction.

4. Patients who had pathological fracture.

Clinical Assessment: A detailed history was obtained and examination was performed especially evaluating the mode of trauma, ASIA grading, sensory level, and any spinal deformity. Full neurological examination was done and documented repeatedly to look for and pick up neurological deficits and deterioration.

Imaging: Plain X-rays in anteroposterior and lateral views were obtained to measure the angular deformity both preand postoperatively; magnetic resonance imaging (MRI) or computed tomography (CT) scans were obtained to further evaluate the important relationships and instability of spine.

\section{Choice of Approach}

The decision on surgical approach is to a great extent based on "The Load Sharing Classification." The posterior approach is generally indicated for patients with score of less than 6 points, whereas the anterior approach should be considered for patients scoring more than 6 points. However, as mentioned earlier, this classification cannot be the sole criteria for decision-making, as the surgical approach of choice also depends on the surgeons' familiarity with the surgical technique, and if anterior surgery is not feasible due to the systemic condition of the patient or inadequate technical facilities, extending posterior instrumentation and fusion length may be the alternative option to restore coronal and sagittal stability, prevent recurrent kyphosis, and promote fusion and post-reduction stability. Thus, factors such as an anesthetic and surgical burden to the patient, morbidity, complication rates, costs, and surgeon's expertise should be taken into account in the choice of surgical approach.

\section{The Thoracoabdominal Approach}

It provides for the best exposure of T12-L2. Generally, resection of rib two levels above the primary pathology is performed. Hence, resection of the 9th rib provides the best window of access to T11-T12, and is accompanied by

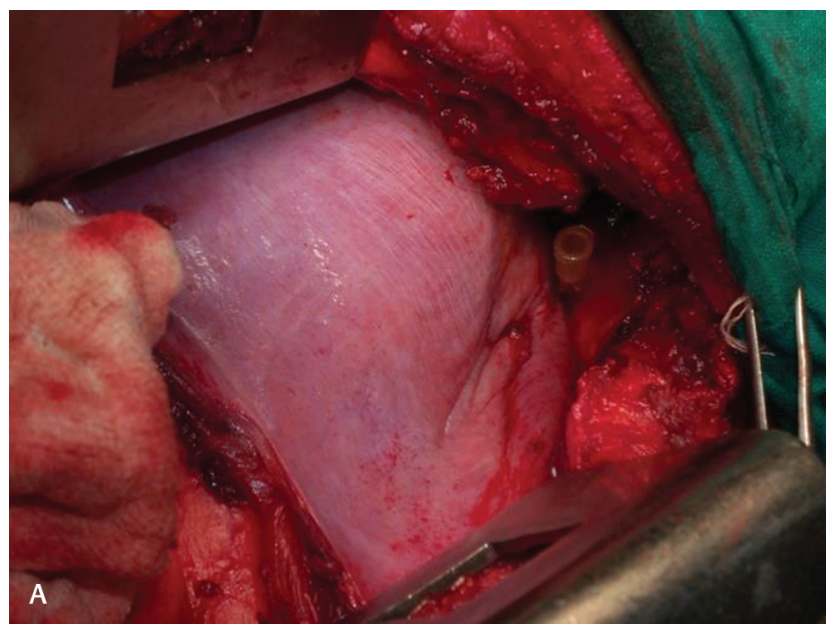

transthoracic approach, whereas exposure of T12-L1 may be accomplished via a thoracoabdominal 10th rib approach.

The patients were placed in lateral decubitus position. A left-sided approach was usually preferred to avoid inferior vena cava and the liver. An incision was made from the lateral border of the par spinal musculature along the required rib to the junction of rib and costal cartilage. The rib was removed. Peritoneum was dissected off the inferior surface of diaphragm. The soft tissue was swept off the thoracic and abdominal surfaces of the diaphragm, which was then incised circumferentially leaving cuff of muscle attached to the chest wall. The crus of diaphragm was cut and elevated off the spinal column.

Deaver retractor was used to retract the peritoneal sac anteromedially, and a large rib retractor opens the intercostal space to reveal the thoracolumbar junction.

Complete discectomy at the level caudal and cephalad to the fracture was performed. A large rongeur was used to remove the anterior cancellous portion of the vertebral body. After the corpectomy was done, titanium mesh cage packed with corpected vertebral body and rib was inserted. Bicortical fixation was performed in all constructs, which were appropriately compressed to improve load sharing. Postoperatively, all patients were managed in a Taylor brace for 3 months (-Figs. 1 and $\mathbf{2}$ ).

\section{Posterior Approach}

Twenty-eight patients were surgically treated with posterior segmental fixation and posterolateral fusion using iliac crest bone graft. We performed pedicle screws fixation at two levels above and one level below the fracture site in most of the patients. In five patients, the lower level was extended to two levels below the fracture vertebra. In most of the cases, transpedicular decompression was done whereas in three patients fracture reduction was achieved by a combination of postural reduction, and by distraction through ligamentotaxis. In two patients, mesh cage was placed after transpedicular decompression at fractured vertebral site. For fusion, bone harvested from the decompression site or iliac crests autograft was used.

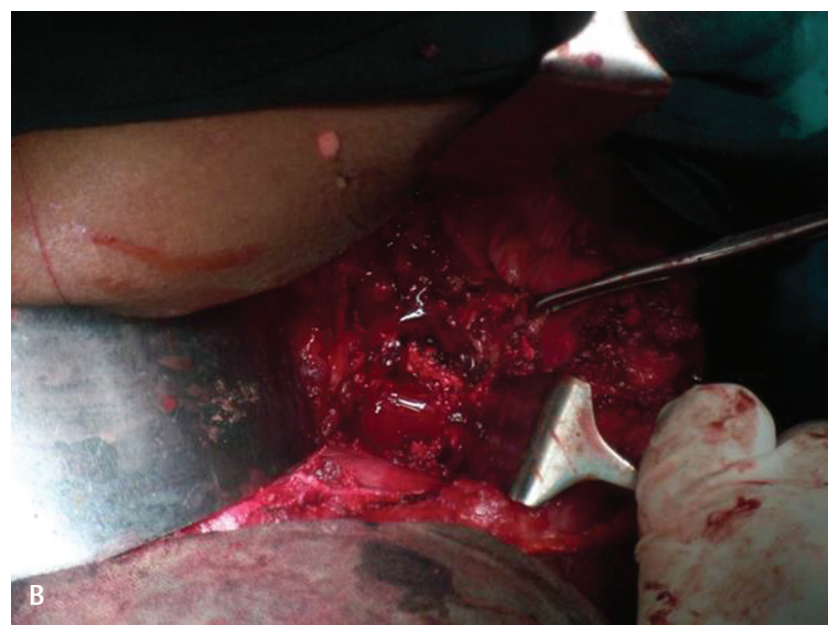

Fig. 1 (A,B) Corpectomy of involved vertebra. 


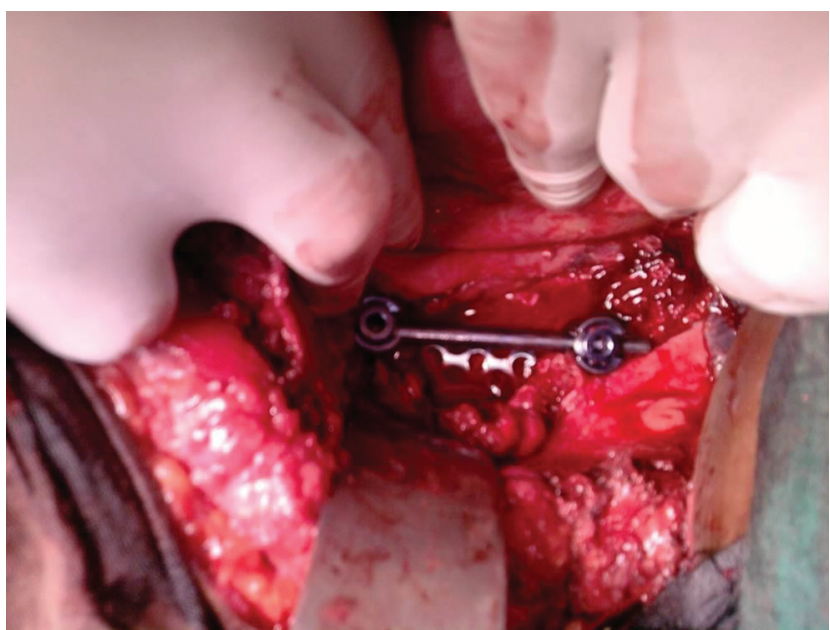

Fig. 2 Cage placement after distraction.

Results were expressed as the mean \pm the standard deviations.

Regardless of which approach was used, the goal of surgery was to decompress the canal, correct the kyphosis, and stabilize the spine. After surgery, patients were mobilized gradually while wearing lumbar orthoses. The patients underwent postoperative radiograph before discharge. They were followed-up 1, 3, and 6 months postoperatively and then annually. The radiographs were obtained with standing lateral views and were analyzed with particular attention paid to the sagittal Cobb's angles at the operation segments.

\section{Result and Analysis}

A total of 60 patients with traumatic spinal injuries were admitted during the study period (December 2011-2013), of which 51 cases were finally selected and taken for operations at our institution during this period for study proper as per the inclusion and exclusion criteria laid down in the Material and Methods section of this study.

These 51 patients were selected and enrolled in the study proper after thorough consent and were thoroughly studied throughout the study period of 24 months. During the study period, 3 patients were lost in follow-up so we had only 48 patients remaining to include in the study.

\section{Age Distribution}

Among our 48 patients, youngest one was of 20 years and eldest of 58 years. Most of the patients (41.66\%) were in the age group of 30 to 40 years. The mean age of our patient population was 38.33 years (- Table $\mathbf{1}$ ).

All the patients in the study populations were thoroughly assessed clinically and grading of completeness of spinal cord injuries was assessed as per ASIA grading of all patients. Patients with ASIA grade E were not included in the study (-Tables 2 and $\mathbf{3}$ ).

Among patients who were decided to be treated by anterior approach, out of 20 patients, 4 were having grade B, 8 grade $\mathrm{C}$, and 8 patients had ASIA grade $\mathrm{D}$.
Table 1 Age-wise distribution of patients with traumatic thoracic/thoracolumbar fracture

\begin{tabular}{|l|l|}
\hline Age (in years) & No. of patients $(\boldsymbol{n}=48)$ \\
\hline $20-30$ & $8(16.66 \%)$ \\
\hline $31-40$ & $20(41.66 \%)$ \\
\hline $41-50$ & $16(33.33 \%)$ \\
\hline$>51$ & $4(8.33 \%)$ \\
\hline
\end{tabular}

Note: In our study, there were 40 (83.33\%) male and 8 (16.66\%) female patients.

Table 2 Distribution of patients according to American Spinal Injury Association (ASIA) grade of spinal injury

\begin{tabular}{|l|l|l|}
\hline Grade & $\begin{array}{l}\text { Completeness of } \\
\text { spinal cord injury }\end{array}$ & $\begin{array}{l}\text { No. of patients } \\
(\boldsymbol{n}=48)\end{array}$ \\
\hline A & Complete $(\mathrm{M}-$, S-) & $4(8.33 \%)$ \\
\hline B & Incomplete $(\mathrm{S}+, \mathrm{M}-)$ & $10(20.83 \%)$ \\
\hline C & Incomplete $(\mathrm{M}<3)$ & $20(41.66 \%)$ \\
\hline D & Incomplete $(\mathrm{M}>3)$ & $14(29.16 \%)$ \\
\hline E & Normal $(\mathrm{S}+, \mathrm{M}+)$ & Not included \\
\hline
\end{tabular}

Abbreviation: $\mathrm{M}$, motor.

Table 3 Distribution of patients having urinary incontinence according to American Spinal Injury Association (ASIA) grade

\begin{tabular}{|l|l|}
\hline ASIA grade & No. of patients $(\boldsymbol{n}=\mathbf{2 5})$ \\
\hline A & $4(16 \%)$ \\
\hline B & $8(32 \%)$ \\
\hline C & $8(32 \%)$ \\
\hline D & $5(20 \%)$ \\
\hline
\end{tabular}

Among patients operated by posterior approach, out of 28 patients, 4 patients had grade A, 6 patients had grade B, 12 patients had grade $C$, and 6 patients had grade $D$.

\section{Preoperative Classification}

Patients were classified preoperatively as per the data provided in $\mathbf{r}$ Tables $\mathbf{4}$ and $\mathbf{5}$.

\section{PostoperativeSurgical Outcome}

Postoperatively, clinical improvement was again assessed by ASIA grading system before discharge, at 6 weeks, 3 months, 6 months, 9 months, 12 months, and then every 6-monthly follow-up. The best grade of the patient achieved in follow-up period was taken as the final ASIA grade. Range of follow-up was from 1 month to 20 months, with a mean of 7.4 months.

\section{In Anterior Approach}

Two patients did not improve, that is, out of four patients having grade $\mathrm{B}$, two remained to have grade $\mathrm{B}$, one patient moved to grade $\mathrm{C}$, and one patient to grade $\mathrm{D}$.

Five patients having grade $\mathrm{C}$ developed power $>4$ and three patients having grade $\mathrm{D}$ developed power $>4$. One patient having grade $\mathrm{B}$ developed power $>4$ and was able to walk 
Table 4 Subclassification of patients falling in different American Spinal Injury Association (ASIA) grades according to operation done

\begin{tabular}{|l|l|l|}
\hline $\begin{array}{l}\text { ASIA } \\
\text { grade }\end{array}$ & $\begin{array}{l}\text { Anterior approach } \\
(\boldsymbol{n}=20)\end{array}$ & $\begin{array}{l}\text { Posterior approach } \\
(\boldsymbol{n}=28)\end{array}$ \\
\hline A & 0 & $4(14.2 \%)$ \\
\hline B & $4(20 \%)$ & $6(21.42 \%)$ \\
\hline C & $8(40 \%)$ & $12(42.85 \%)$ \\
\hline D & $8(40 \%)$ & $6(21.42 \%)$ \\
\hline
\end{tabular}

Table 5 Classification of patients on the basis of mobility in anterior and posterior approaches preoperatively

\begin{tabular}{|l|l|l|}
\hline Type of patients & $\begin{array}{l}\text { Anterior } \\
\text { approach }(\boldsymbol{n}=\mathbf{2 0})\end{array}$ & $\begin{array}{l}\text { Posterior } \\
\text { approach }(\boldsymbol{n}=\mathbf{2 8})\end{array}$ \\
\hline Bed ridden & $13(65 \%)$ & $22(78.57 \%)$ \\
\hline Walks with support & $4(20 \%)$ & $3(10.71 \%)$ \\
\hline $\begin{array}{l}\text { Walks without } \\
\text { support }\end{array}$ & $3(15 \%)$ & $3(10.71 \%)$ \\
\hline
\end{tabular}

with support. So, in total, nine patients were able to walk with support. Rest eight patients could walk without support.

Out of 20 patients, 3 (15\%) patients were bed ridden, 9 (45\%) persons could walk with support, and 8 (40\%) without support.

\section{In Posterior Approach}

Out of four patients having grade $A$, three remained in grade A while one improved to grade $C$ with power of 2 . Among six patients with grade $B$, two were able to walk with support and four patients improved to grade $\mathrm{C}$. Among 12 patients having grade C, 5 were able to walk with support and 2 without support. In grade $\mathrm{D}$, out of six patients, one patient was not able to walk as he had power of 3 , while three patients were able to walk with support and two patients without support.

So, out of 28 patients, 14 (50\%) patients were bed ridden, $10(35.71 \%)$ patients were able to walk with support, and 4 (14.28\%) patients without support.

\section{Follow-Up Kyphotic Angle}

Our patient population postoperatively was subjected to serial radiographs. Initially on third postoperative day check digital X-rays, both anteroposterior and lateral views were taken. Out of 48 , only 43 came for regular follow-ups postoperatively, that is, 18 in anterior group and 25 in posterior group. They were subjected to serial radiographs. CT and MRI scans were obtained in selected cases where digital X-rays were not informative or contradictory.

Kyphotic angle changes were seen in 16 patients out of 18 in anterior group and 20 patients in posterior group out of 25.

Out of 18 patients in the anterior group, 2 showed no change in angle, 2 showed increase in kyphotic angle (deterioration), and 14 showed reduction in kyphotic angle of 1 to 10 degrees (improvement).with mean improvement of 4.07 degrees.

In the posterior group, out of 25 patients, there was no change in kyphotic angle in 5 patients, 7 patients showed improvement of 1 to 8 degrees (reduction in kyphotic angle), whereas 13 patients showed deterioration of 1 to 12 degrees. The mean improvement was 2.14 degrees in 7 patients and mean deterioration was 4.92 degrees (-Figs. $3-5$ ).

\section{Patients with Urinary Incontinence}

In the anterior group, out of 20 patients, 8 patients had urinary continence before operation. After operation, 3 patients improved and rest 5 continued to have incontinence.

In the posterior group, out of 28 patients, 17 had urinary incontinence. Only 2 patients improved and rest 15 patients continued to have urinary incontinence (-Table 6 ).

\section{Statistical Analysis of Clinical Assessment and Results}

On comparing the two groups preoperatively after applying chi-square test, the $p$-value was 0.56 , which is $>0.05$. Hence, there was no statistically significant difference between the two groups ( - Table 7 ).

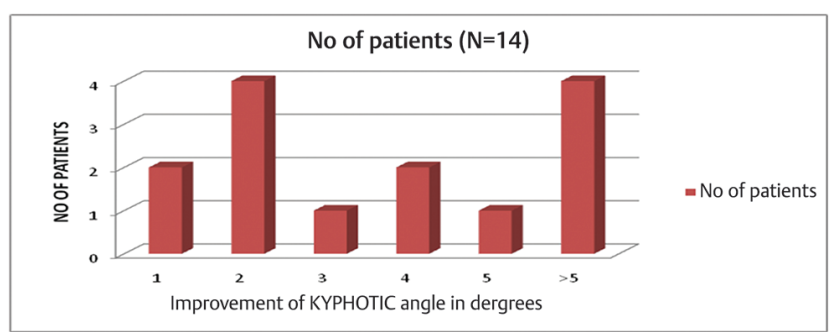

Fig. 3 Patients showing changes in kyphotic angle after operation through anterior approach.

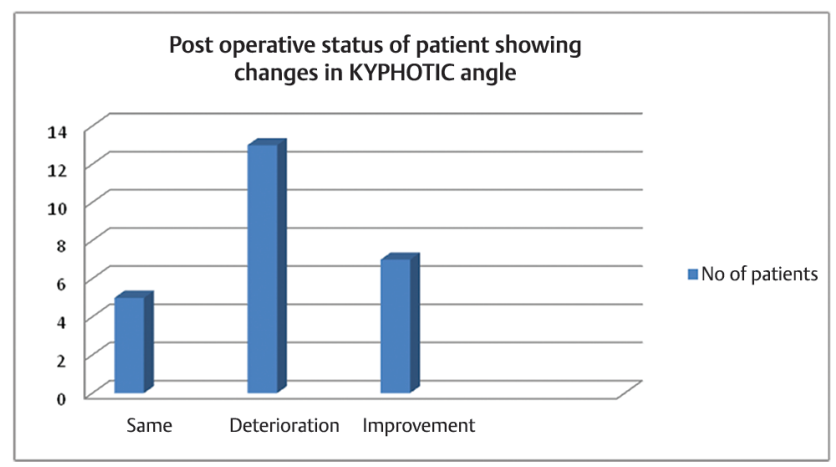

Fig. 4 Number of patients showing changes in kyphotic angle in posterior approach group.

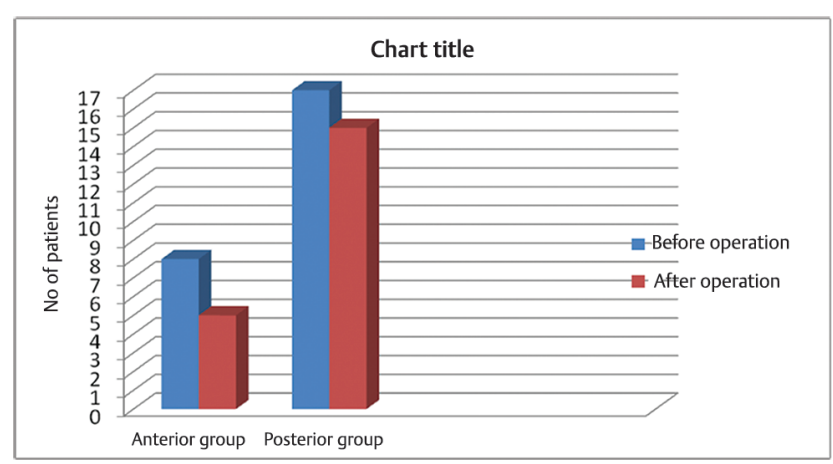

Fig. 5 Patients showing changes in urinary incontinence before and after operation through anterior approach or posterior approach. 
Table 6 Urinary inconsistency after surgery

\begin{tabular}{|l|l|l|}
\hline Incontinence & $\begin{array}{l}\text { Posterior group } \\
(N=17)\end{array}$ & $\begin{array}{l}\text { Anterior group } \\
(N=8)\end{array}$ \\
\hline Corrected & $2(11.76 \%)$ & $3(37.5 \%)$ \\
\hline Not corrected & $15(88.23 \%)$ & $5(62.5 \%)$ \\
\hline
\end{tabular}

Table 7 Preoperative neurological status of patients

\begin{tabular}{|l|l|l|l|}
\hline Status & $\begin{array}{l}\text { Posterior } \\
\text { group }\end{array}$ & $\begin{array}{l}\text { Anterior } \\
\text { group }\end{array}$ & $\chi^{2}$ test \\
\hline Bed ridden & 22 & 13 & \multirow{2}{*}{$\begin{array}{l}\chi^{2}(2)=1.16 \\
p=0.56\end{array}$} \\
\cline { 1 - 2 } Walks with support & 3 & 4 & \multirow{2}{*}{} \\
\cline { 1 - 3 } Walks without support & 3 & 3 & \\
\cline { 1 - 3 } Total & 28 & 20 & \\
\hline
\end{tabular}

\section{Postoperatively}

In the postoperative group, the $p$-value is 0.025 , which is $<0.05$. Hence, the result is statistically significant after using chi-square test. There was statistically significant improvement in the postoperative group in anterior approach as compared with posterior approach ( - Table 8 ).

$$
\begin{array}{r}
\chi^{2}(2)=7.375 \\
p=0.025
\end{array}
$$

\section{Statistical Analysis of Kyphotic Angle}

Comparing the kyphotic angles in two groups, $p$-value in deteriorated group is 0.014 , which is $<0.05$, so the result was statistically significant. The posterior approach group showed statistically significant deterioration in kyphotic angle whereas on comparing the improvement in kyphotic angle between anterior and posterior groups, $p$-value was found to be $0.004(<0.05)$. So, there was statistically significant improvement in kyphotic angle in anterior approach group (-Table 9).

\section{Statistical Analysis of Urinary Incontinence}

$$
p=0.33
$$

On comparing the two groups by chi-square test, no statistical difference was found ( $p>0.05$ ) regarding improvement in urinary incontinence during the follow-up period (-Table 10).

\section{Complications}

Three patients in the posterior approach group developed superficial skin infections, which were managed conservatively by appropriate antibiotic treatment. Three patients in the anterolateral approach group required prolonged chest tube after surgery due to opening of the pleura cavity during the operation. Two patients who underwent anterolateral approaches developed low thoracic dermatomal pain from intercostal neuralgia that was improved with pain medication. One patient had an aortic injury during exposure that was successfully repaired by cardio-thoracic surgeon and the patient had an uneventful course. There were no other complications such as neural structure injury and hardware failure.

\section{Discussion}

Almost two-thirds of all traumatic TL spine injuries occur at the TL junction, most frequently at L1, followed by T12. From an anatomical standpoint, the ideal treatment of unstable TL junction fractures should consist of complete kyphosis correction and optimal spinal canal decompression in case of a neurological deficit. The treatment of TL junction burst fractures remains very controversial for several reasons. Anterolateral decompression in comparison to posterior decompression allows direct decompression of ventral osseous and offering superior canal clearance as compared with the posterior approach (ligamentotaxis, posterolateral decompression techniques).

\section{Surgical Outcome in Terms of Motor Functions}

Robert and Kumar ${ }^{5}$ usually perform posterior surgery on cases with ASIA class A spinal cord injuries. The extent of instrumentation is usually two or three levels above and two levels below.

Cases with partial neural deficits are ideal candidates for anterior decompression as they have the greatest chance for

Table 8 Postoperative neurological status of patients

\begin{tabular}{|l|l|l|l|}
\hline & $\begin{array}{l}\text { Anterior } \\
\text { Approach }\end{array}$ & $\begin{array}{l}\text { Posterior } \\
\text { approach }\end{array}$ & $\begin{array}{l}\text { Total no. of } \\
\text { patients }\end{array}$ \\
\hline Bed ridden & 3 & 14 & 17 \\
& 7.08 & 9.92 & \\
$(2.35)$ & $(1.68)$ & \\
\hline $\begin{array}{l}\text { Walks with } \\
\text { support }\end{array}$ & 9 & 10 & 19 \\
& 7.92 & 11.08 & \\
Walks with- & 8 & $(0.11)$ & \\
out support & 5.00 & 4 & 12 \\
& $(1.80)$ & $\begin{array}{l}7.00 \\
(1.29)\end{array}$ & \\
\hline & 20 & 28 & 48 \\
\hline
\end{tabular}

Table 9 Statistical analysis of kyphotic angle

\begin{tabular}{|l|l|l|l|}
\hline $\begin{array}{l}\text { Kyphotic } \\
\text { angle }\end{array}$ & $\begin{array}{l}\text { Anterior } \\
\text { group } \\
\left(N_{1}=18\right)\end{array}$ & $\begin{array}{l}\text { Posterior } \\
\text { group } \\
\left(N_{2}=25\right)\end{array}$ & $\begin{array}{l}\text { Z-test } \\
\text { or } p \text {-value }\end{array}$ \\
\hline Same & $2(11.1 \%)$ & $5(20 \%)$ & $\begin{array}{l}Z=0.36 \\
p=0.718\end{array}$ \\
\hline Deteriorated & $2(11.1 \%)$ & $13(52 \%)$ & $\begin{array}{l}Z=2.45 \\
p=0.014\end{array}$ \\
\hline Improved & $14(77.8 \%)$ & $7(28 \%)$ & $\begin{array}{l}Z=2.91 \\
p=0.004\end{array}$ \\
\hline
\end{tabular}

Table 10 Urinary incontinence

\begin{tabular}{|l|l|l|l|}
\hline Incontinence & $\begin{array}{l}\text { Posterior } \\
\text { group }\end{array}$ & $\begin{array}{l}\text { Anterior } \\
\text { group }\end{array}$ & $\chi^{2}$ test \\
\hline Corrected & 2 & 3 & $\begin{array}{l}\chi^{2}(2)=0.93 \\
\text { (Yates corrected }) \\
p=0.33\end{array}$ \\
\hline Not corrected & 15 & 5 & \\
\hline Total & 17 & 8 & \\
\hline
\end{tabular}


neurological recovery. In their experience, blood loss, neurological outcomes, and overall management of morbidity and mortality have been very low in either approach. The most important factor determining the operative approach is the individual surgeon's own outcomes, which lead to the best neurological and functional outcomes. In the overwhelming majority of patients, successful decompression and stabilization/fusion can be accomplished by either approach.

Belanger et $\mathrm{al}^{6}$ reported that even in cases of long-standing compression, anterior decompression can result in modest improvements in neurological function. The results of surgical decompression (SD) in 59 patients with neurological deficits secondary to thoracic or lumbar fractures were evaluated at a mean of 3.7 years after injury. The purpose was to determine whether SD could be correlated with subsequent neurological outcome. Follow-up neurological evaluations showed a greater neurological improvement in the 20 patients who were treated with anterior spinal SD as compared with the 39 patients who received posterior or lateral SD (88\% vs. $64 \%)$.

Bradford and McBride ${ }^{7}$ reported an average $25.9 \%$ of residual canal compromise following posterior surgery compared with less than $1 \%$ after anterior decompression.

Humphries et $\mathrm{al}^{8}$ were of the opinion that anterior grafting favored fusion because of better blood supply and bone contact, and the fact that the graft is under compression.

\section{Outcome in Relation to Kyphotic (Cobb's) Angle}

In Ghanayem and Zdeblick ${ }^{9}$ study, 10 of 12 patients who underwent anterior arthrodesis using the $Z$ plate thoracolumbar plating system after a one-stage anterolateral decompression and reduction procedure for burst fractures from T9 to L3 maintained their postoperative sagittal alignment or a significant portion of their kyphosis reduction. Two patients with severe kyphotic deformities greater than 50 degrees lost 10 degrees and 20 degrees of their reduction, respectively, at last follow-up.

Hammad and Mohamed ${ }^{10}$ in their study found that in anterior approach the kyphotic angle improved from the mean angle 8.8 degrees (range from-6 to 20 degrees) before surgery to the mean angle-1 degree (range from-10 to 4 degrees) after surgery and final follow-up. A significant difference was seen between kyphotic angle preoperatively and at final follow-up ( $p=0.0001)$ in all cases.

\section{Changes in Bladder Symptom}

Chiu and Liao ${ }^{11}$ in their study of pure conus medullaris syndrome with L1 burst fracture found that despite surgical treatment regardless of approach, only one-half of the patients regained normal bladder and sexual function.

Elsawaf ${ }^{12}$ in their study showed that in the posterior approach group, 18 patients had urinary symptoms in the form of urine retention. With continuous follow-up, 11 patients showed progressive improvement and all of them were not using a urinary catheter anymore. On the other hand, the anterior group showed 16 patients of acute urinary dysfunction: 13 of them had complete improvement in the problem by the follow-up period; the other 3 patients had persistent urinary dysfunction but were in need of only intermittent catheterization with bladder distension. His follow-up duration was 4.9 years.

We, however, could not find any significant difference in the postoperative improvement in bladder symptoms in either approach or the two approaches were similar in outcome as far as bladder symptoms were considered.

But here also we would like to emphasize the limitation of short follow-up, small sample size, and proper bladder exercises. In the long-term follow-up, the results may vary.

Analysis of our clinical outcome demonstrates that neurological improvement was documented in our patients regardless of which approach was used. The results were better with the anterior approach since $~ 80 \%$ of the patients in the anterior study group were able to walk, either with or without support. Radiological results in our study show that $77.77 \%$ showed improvement (reduction) in kyphotic angle whereas in the posterior group only $28 \%$ showed improvement in kyphotic angle. Currently, guidelines based on randomized trials for the treatment of thoracolumbar burst fractures are unavailable. In terms of urinary incontinence, there was no statistical improvement in the anterior group as compared with posterior group or vice versa. Verlaan et $\mathrm{al}^{13}$ conducted a literature review of 132 papers, involving 5,748 patients with thoracic and lumbar fractures treated with posterior, anterolateral, or combined approaches. They concluded that evidence-based guidelines for the treatment of these fractures were absent and suggested that, for a better comparison of surgical techniques, randomized controlled trials were necessary. We agree with their conclusions, but we need to consider several parameters before we chose the selection of treatment options. This selection should be based on clinical and radiological findings such as deformity angulation, residual canal diameter, and vertebral body height including neurological deficit.

\section{Conclusion}

With all the available material and methods and after analyzing all the results and statistical values, this study concluded that:

- Traumatic thoracic/thoracolumbar injuries (41.66\%) are more common in persons of productive age group (3140 years) with male preponderance ( $\mathrm{M}>\mathrm{F}, 83.33 \%$ ).

- More persons were able to walk with or without support in anterior group (85\%) whereas in posterior group the improvement was less (50\%).

- There is statistically significant difference in change of kyphotic angle in long-term follow-up. In the anterior group, $77.77 \%$ showed improvement (reduction) in kyphotic angle whereas in posterior group only $28 \%$ showed improvement in kyphotic angle.

- In terms of urinary incontinence, there was no statistical improvement in anterior group as compared with posterior group or vice versa, with only $37.5 \%$ showing improvement in anterior group as compared with posterior group (11.76\%). 
In conclusion, it can be said that the anterior approach provides a better outcome in terms of improvement in motor and sensory function, as well as more decrease in kyphotic deformity as compared with posterior approach. But there seems to be no significant difference in terms of autonomic improvement in form of bladder continence.

There were certain limitations in our study. The sample size was not very big; moreover, the long-term follow-up may have some impact on the kyphotic angulation regardless of approaches.

\section{Funding}

None.

\section{Conflict of Interest}

None declared.

\section{References}

1 Wood K, Buttermann G, Mehbod A, Garvey T, Jhanjee R, Sechriest V. Operative compared with nonoperative treatment of a thoracolumbar burst fracture without neurological deficit. A prospective, randomized study. J Bone Joint Surg Am 2003;85(5):773-781

2 Siebenga J, Leferink VJ, Segers MJ, et al. Treatment of traumatic thoracolumbar spine fractures: a multicenter prospective randomized study of operative versus nonsurgical treatment. Spine 2006;31(25):2881-2890

3 Tezeren G, Kuru I. Posterior fixation of thoracolumbar burst fracture: short-segment pedicle fixation versus long-segment instrumentation. J Spinal Disord Tech 2005;18(6):485-488
4 Vaccaro AR, Lim MR, Hurlbert RJ, et al; Spine Trauma Study Group. Surgical decision making for unstable thoracolumbar spine injuries: results of a consensus panel review by the Spine Trauma Study Group. J Spinal Disord Tech 2006;19(1):1-10

5 Robert F, Kumar S. Decision-making in burst fractures of the thoracolumbar and lumbar spine. Indian J Orthop 2007; 41(4):268-276

6 Belanger TA, Roh JS, Hanks SE, Kang JD, Emery SE, Bohlman $\mathrm{HH}$. Ossification of the posterior longitudinal ligament. Results of anterior cervical decompression and arthrodesis in sixty-one North American patients. J Bone Joint Surg Am 2005;87(3):610-615

7 Bradford DS, McBride GG. Surgical management of thoracolumbar spine fractures with incomplete neurologic deficits. Clin Orthop Relat Res 1987;(218):201-216

8 Humphries AW, Hawk WA, Berndt AL. Anterior interbody fusion of lumbar vertebrae: a surgical technique. Surg Clin North Am 1961;41:1685-1700

9 Ghanayem AJ, Zdeblick TA. Anterior instrumentation in the management of thoracolumbar burst fractures. Clin Orthop Relat Res 1997;(335):89-100

10 Hammad WA, Mohamed AB. Anterolateral approach for unstable lumbar burst fracture with anterior compression. Open J Modern Neurosurgry 2018;8(2):201-214

11 Chiu PY, Liao JC. Surgical outcomes in thoracolumbar fractures with pure conus medullaris syndrome. Biomed J 2019;42(4):277-284

12 Elsawaf A. Late outcome of ant vs. post fixation for thoracolumbar fractures. Int Res J Basic Clin Studies 2013;1(2):22-31

13 Verlaan JJ, Diekerhof CH, Buskens E, et al. Surgical treatment of traumatic fractures of the thoracic and lumbar spine: a systematic review of the literature on techniques, complications, and outcome. Spine 2004;29(7):803-814 